\title{
Sentimiento, realidad y belleza: un acercamiento a las ideas estéticas de Xavier Zubiri
}

\section{Planteamiento del problema: una investigación exclusivamente cen- trada en la belleza}

A. Ferraz Fayos, en su monografía Zubiri: el realismo radical (1995), afirma que, sin lugar a dudas, existe "una filosofía zubiriana", y que dicha filosofía se articula en torno a tres "ideas matrices": la "idea de realidad", la "idea del conocimiento" y la "idea del hombre", de las que parte Zubiri para abordar los problemas más específicos de Dios, el mundo, la esencia, las relaciones entre sensibilidad y entendimiento, o entre razón y verdad, así como aquellas cuestiones que tienen que ver con la sociedad, la historia, la moralidad o la religión'1.

Si Zubiri hubiese leído este comentario sobre su filosofía, seguramente hubiese estado de acuerdo con él, pero habría detectado una importante ausencia en la serie de conceptos mencionados: no se cita entre ellos, en efecto, el problema de lo bello, que, ha indicado Diego Gracia, constituye uno de los ejes básicos de su pensamiento ${ }^{2}$. En el presente artículo me propongo profundizar en los puntos fundamentales de la estética y la teoría del arte zubirianas, enlazándolos primero con otras propuestas estéticas, para pasar luego a estudiar qué relación existe entre las ideas planteadas en este terreno por el filósofo vasco y el resto de su sistema, haciendo especial hincapié en los vínculos que establece Zubiri entre el concepto de "belleza" y los demás trascendentales.

9.

${ }^{1}$ Cf. Ferraz FAyos, A., Zubiri: el realismo radical, Ed. Pedagógicas, Madrid, 1995, p.

2 Cf. GRACIA, D., "Introducción" a LÓPEZ ARANGUREN, J. L., Etica y estética en $X$. Zubiri, Trotta / Fundación X. Zubiri, Madrid, 1996, p. 13 y ss. 
Zubiri se ocupó de analizar el problema de la estética en el Curso "Reflexiones filosóficas sobre lo estético", impartido los días 15 y 22 de abril de $1975^{3}$, y recogido actualmente en la Tercera Parte del volumen titulado Sobre el sentimiento y la volición, publicado por la Editorial Alianza en 1992, en colaboración con la Fundación que lleva su nombre.

Desde la Introducción al citado Curso, aclara Zubiri que su objetivo es analizar el fenómeno estético, interpretando el término "estético" como sinónimo de "lo bello", aun siendo consciente de que ambos términos no resultan en modo alguno equivalentes. También indica explícitamente que su estudio no se ocupa del problema del arte, por considerar que el término "belleza" trasciende con mucho el arte propiamente dicho (ya que incluiría tanto la belleza natural como la belleza artística), y porque tampoco está claro que la belleza sea el objeto fundamental del arte ${ }^{4}$. Su objetivo, afirma, es únicamente "preguntar qué es lo que se entiende al decir de algo que es, pura y simplemente, bello"5: no se trata, por tanto, de analizar ni las cosas bellas, ni un determinado "canon de la belleza" (por ejemplo, el "canon" de Policleto o Praxiteles), sino única y exclusivamente de averiguar sin más en qué consiste que algo sea bello; la concreción de la belleza, es decir, "qué cosas son bellas, cómo lo son y cuándo", son temas que Zubiri decide pasar por alto en su indagación.

Añade, asimismo, que para él la reflexión estética no se centra, en principio, en la reflexión sobre la obra de arte -aunque, infiel a su propósito inicial, abordará también este punto, más avanzado el curso-, sino que implica más bien una indagación sobre el sentimiento estético, "o, más exactamente, [sobre] cómo afecta estéticamente la realidad al sujeto"6. Como estamos viendo, se trata de un planteamiento que opta decididamente por una visión ahistórica y trascendental de la belleza; una perspectiva que busca indagar cuáles son las estructuras fundamentales de tal categoría, con independencia de cualquier circunstancia histórico-social concreta en la que ésta pueda aparecer. Aunque es evidente que un enfoque tan reductor merma el potencial hermenéutico de la investigación zubiriana, considerado desde otro punto de vista, tiene la ventaja de asegu-

${ }^{3}$ La noticia la recoge el diario ABC de fecha 25-04-1975, p. 35: "Xavier Zubiri en la Sociedad de Estudios y Publicaciones pronunció su Segunda lección sobre filosofía de la estética".

4 ZUBIRI, X., Sobre el sentimiento y la volición (SV), Alianza / Fundación X. Zubiri, Madrid, 1992, p. 323.

5 Ibidem.

6 BORREGO, J., "Estética en X. Zubiri", en: http://usuarios.lycos.es/javierborrego/ private/trabajos/esteticazubiri.html, p. 2. 
rarle un grado de universalidad y profundidad muy amplio 7 : Zubiri no trata, en efecto, de presentar una estética hecha a la medida de artistas o historiadores del arte, sino de fundar una estética que pueda merecer la aprobación de los filósofos.

\section{Breve repaso del problema de la belleza a lo largo de la historia de la filosofia}

Como preámbulo a su estudio, Zubiri presenta una sucinta exposición del problema de la belleza, tal como ha sido afrontado a lo largo de la historia de la filosofía. Comienza, como cabía esperar, examinando las tesis de Platón y Aristóteles: para ambos filósofos, lo bello aparece como sỳmmetron, es decir, como una cualidad vinculada a aquel objeto que tiene simetría, ordenación (táxis), y se encuentra circunscrito por una forma limitada, lo que se corresponde con la práctica misma del arte griego, que se basa en la proporción, correspondencia rigurosa de partes, ritmo, armonía y equilibrio de formas, etc., todo lo cual da lugar al mencionado canon griego de la belleza. Asimismo, tanto Platón como Aristóteles contraponen la belleza de lo simétrico y ordenado a la belleza -entendida en sentido traslaticio- que se encuentra en la praxis, es decir, en las acciones realizadas por el ser humano ${ }^{8}$.

Otra definición tradicional de belleza la da Plotino, al señalar en sus Enéadas que la belleza no es la idea misma, como creía Platón, sino más bien la manifestación de la idea, más concretamente, "el resplandor que se trasluce de la proporción"9. En pleno siglo XIX, Hegel recogerá a su manera esta tesis en las Lecciones sobre la estética, donde, como es sabido, define la belleza como "la apariencia sensible de la Idea" (das sinnliche

7 Ha sido Alfonso López Quintás quien ha destacado esta tendencia general de la obra de Zubiri "a lo profundo", que no podía faltar tampoco, como es obvio, en su abordamiento del problema estético: Cf. LÓPEZ QUINTÁs, Pensadores cristianos contemporáneos I: Haecker, Ebner, Wust, Przywara, Zubiri, BAC, Madrid, 1968, p. 308.

${ }^{8}$ En El Sofista, 228 a-d, Platón define la fealdad como ametría ("Y, en la fealdad, ¿ves

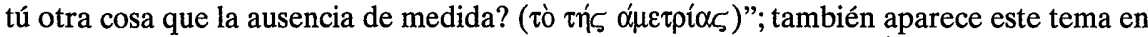
El Político, 284b (Cf. PlATón, Obras completas, Aguilar, Madrid, 19794, pp. 1010 y 1079-80). Aristóteles, por su parte, en Metafísica, XIII, 3: 1078a36b1, dice que "las formas más estimadas de lo bello son el orden (táxis), la simetría (symmetría) y la limitación (horisménon)"; y en Metafísica, XIII, 3: 1078a31-32, señala que "el bien y lo bello se diferencian entre sí, porque el bien siempre se da donde hay acción, mientras que la belleza se da también en los seres inmóviles." (Cf. ARISTÓTELES, Obras, Aguilar, Madrid, 1973², p. 1065).

9 Enéada VI, 7, 22, cit. en:TATARKIEWICZ, W., Historia de la estética. I. La estética antigua, Akal, Madrid, 1987, pp. 335-336. 
Scheinen der Idee $)^{10}$, puesta de manifiesto a través de las cosas reales y concretas.

Ya en el mundo medieval, San Agustín, en la línea de Plotino, definirá la belleza como "esplendor", pero no de la idea, sino de "lo verdadero" (splendor veri) ${ }^{11}$, planteamiento retomado el siglo pasado por otro importante pensador alemán, Heidegger, quien en El origen de la obra del arte define la belleza como "uno de los modos de presentarse la verdad como desocultamiento"12.

La última referencia que da Zubiri-quien, dicho sea de paso, no presta la más mínima atención a ningún planteamiento de índole vitalista (Nietzsche), sociologista (Marx) o historicista (Dilthey, Ortega y Gasset), por citar sólo algunos, quizás debido a la orientación en último término metafísica que anima todo su análisis- corresponde a Tomás de Aquino, y a la definición de las cosas bellas que ofrece en la Summa Theologica como aquellas que "agradan a la vista"13: se trata de objetos que resultan placenteros, agradables, por detentar un orden estructurado, que suscita nuestra delectación.

\section{Los dos aspectos fundamentales del problema de la belleza}

De lo hasta aquí expuesto, Zubiri concluye que el problema de la belleza incluye dos dimensiones o aspectos fundamentales:

10 HeGEL, G. W. F., Lecciones sobre la estética, Akal, Madrid, 1989, p. 85.

11 Cf. TAtarkiewICZ, W., Historia de la estética. II. La estética medieval, Akal, Madrid, 1989, pp. 69-71.

12 HeIDEGGER, M., "El origen de la obra de arte" (Der Ursprung des Kunstwerkes), en: Caminos del bosque, Alianza, Madrid, 1995, p. 45.

13 TOMÁs DE AQUINO, Summa Theologica I, q. 5, a. 4 ad 1: "Se llama bello aquello que agrada a la vista" ("Pulcra enim dicuntur quae visa placent)"; y en Summa Theologica I-II, q. 27, a.1 ad 3 continúa: "Lo bello y lo bueno son lo mismo, difiriendo únicamente por la razón. Porque lo bueno es aquello que todos apetecen, de manera que la razón de lo bueno es aquello en lo que se calma el apetito. Pertenece a la naturaleza de la belleza aquello cuya visión o conocimiento colma el deseo. Por eso, también aquellos sentidos que son más cognoscitivos -como la vista y el oído, que sirven a la razón-aspiran principalmente a la belleza: así hablamos de bellas visiones y de bellos sonidos; sin embargo, para las percepciones de los demás sentidos no usamos el término "belleza": no decimos bellos sabores y olores. $Y$ así sucede que la belleza añade al bien una ordenación a la facultad cognoscitiva, de manera que se llama "bueno" aquello que colma el deseo, mientras que "bello" se aplica a aquello cuya percepción misma complace." (TATARKIEWICZ, W., Historia de la estética. II La estética medieval, Op. Cit., pp. 269-270) 
a) Por una parte, el problema del sentimiento (referido al "esplendor" y al "orden de lo que deleita"): todo análisis sobre la belleza ha de incluir una referencia al sentimiento.

b) Por otra parte, el problema del objeto o realidad sobre el que recae dicho sentimiento, esto es, el problema de lo bello (pulchrum).

Zubiri afronta, en consecuencia, el problema de la belleza desde dos puntos de vista distintos, aunque complementarios: un punto de vista "sentimental", en el que se trata de averiguar de dónde surge y en qué consiste el denominado "sentimiento estético", y un punto de vista "objetivo", o, más precisamente, "real", en el que habrá que determinar en qué consiste aquello hacia lo que apunta el sentimiento estético ${ }^{14}$.

\section{El problema del sentimiento}

\section{1. ¿Qué se entiende por "sentimiento"?}

En la filosofía tradicional -término que podría incluir el pensamiento desarrollado desde Platón hasta principios del siglo XVIII, a pesar de sus innumerables variantes-, los sentimientos se concibieron como modalidades del apetito, entendiendo por "apetencia" la simple tendencia hacia algo que se relaciona con dicha apetición. Sentimiento equivalía, por tanto, a tendencia, y los diversos sentimientos a las modalidades adoptadas por ésta última: los "modos tendenciales", que los filósofos racionalistas del siglo XVII (Descartes o Spinoza) llamaban "pasiones" del alma.

En esta concepción, procedente en último término de la Escolástica, las tendencias se referían siempre a cosas reales, no a objetos imaginarios o intencionales, simples entes de razón o vagos proyectos de la fantasía. Los apetitos se caracterizaban por tener dos "dimensiones": tender hacia lo considerado como bueno y rehuir lo que se presiente como malo. Por último, cuando las tendencias se dirigen sin más a un objeto, recibían el nombre de "apetitos concupiscibles", dando lugar a dos sentimientos fundamentales: amor y odio (de los que luego se derivan la alegría, la tristeza, el deseo de un objeto presente o ausente, o la fuga del mismo); en cambio, aquellos apetitos que tienen que ver con la dificultad de lograr su ob-

14 SV, p. 326. 
jeto recibían el nombre de "pasiones irascibles", como la esperanza, la desesperación, la audacia, el temor y la ira.

Dentro de los sentimientos, los escolásticos distinguían, además, dos estratos completamente distintos e incomunicables entre sí: los "apetitos sensibles" y los "apetitos racionales"; los primeros son las tendencias animales del hombre; los segundos derivan de la voluntad, que es un apetito racional. Aquéllos son apetitos inferiores, "pasiones" en sentido estricto; éstos son apetitos, no pasiones.

Frente a estas enmarañadas distinciones, propias de la filosofía escolástica, Zubiri plantea tres cuestiones:

$1^{a}$. Decir que el objeto del sentimiento ha de ser "real" no aclara nada mientras no se defina el término "realidad"; en efecto: ¿qué significa que el sentimiento tiene como objeto algo real, no imaginario? Parece evidente que resulta necesario aclarar primero qué se entiende por "realidad".

$2^{\text {a }}$ ¿Es cierto que hay sentimientos "superiores" e "inferiores"? ¿No habrá un solo apetito, dentro del cual pueden distinguirse dos momentos diferentes, con lo que únicamente tendríamos que hablar de sentimientos humanos? ¿No sería mejor, en suma, afirmar la unidad del sentir en el hombre?

$3^{\mathrm{a}}$. Por último, ¿pueden identificarse sin más sentimientos y tendencias?; pues parece haber sentimientos, o pasiones anímicas que no tienen nada que ver con tendencia alguna: cabría pensar pues que "los sentimientos no son tendenciales, ya que el hombre puede sentirse bien o mal sin que las cosas afecten a su sentimiento. El sentimiento es un estado, y no tiene por qué estar fundado en el deseo"15.

Zubiri cree, pues, que sentimiento y tendencia no se identifican, sino que el sentimiento es algo más elemental y difícil de explicar, en concreto "la forma en que uno "está'; es estado"16. Y así lo entendieron, efectivamente, numerosos pensadores de los siglos XVII y XVIII, como Schulze, Mendelssohn, Tetens o Kant en la Crítica del Juicio; distinguían tres funciones humanas: la inteligencia, el sentimiento y la voluntad ${ }^{17}$; mientras la

15 Borrego, J., Op. Cit., p. 3.

16 SV, p. 331; cf., además: LÓPEZ QUINTÁs, A., "El sentido estético y la fruición de la realidad", en: LÓPEZ ARANGUREN, J. L. (et al.), Etica y estética en X. Zubiri, Op. Cit., pp. 142 y ss.

17 "Todas las facultades del alma o capacidades pueden reducirse a tres que no se dejan deducir ya de una base común, y son: la facultad de conocer, el sentimiento de placer 
inteligencia trata de conocer lo que las cosas son, y la voluntad decidir sobre la bondad de las cosas, los sentimientos aparecen como modos subjetivos, íntimos, de sentirse: estados íntimos subjetivos.

El problema estriba, sin embargo, en que, como señala Zubiri, aquí no se definen claramente ni la "intimidad", ni el "sujeto"; lo único que parece claro es que el sentimiento "es un modo de estar, un modo de sentirse”; pero ¿cuál? Para averiguarlo, el pensador vasco considera necesario añadir un matiz muy importante, que se corresponde con el realismo radical característico de su filosofía, desde cuyo punto de vista el sentimiento no es otra cosa que "un modo de estar realmente en la realidad, (...) de sentirse realmente en la realidad"18.

\subsection{Sentimiento y realidad}

La definición que Zubiri ofrece del sentimiento hay que enmarcarla dentro de su antropología filosófica, en la cual el hombre no es sino un animal más, aunque dotado de una serie de notas psíquicas, que, en interacción con el conjunto de notas que constituyen su corporalidad, le capacitan para abrirse a la impresión de realidad ${ }^{19}$; por eso, Zubiri define al hombre como un "animal de realidades" 20 . Porque, en efecto, el animal recibe estímulos, que modifican su tono vital y suscitan en él diversas respuestas; en cambio, el hombre se encuentra, por su inteligencia sentiente, instalado en la realidad, y está obligado de por vida a "hacerse cargo" de ella ${ }^{21}$; de manera que no sólo capta el estímulo, sino que lo intelige como

y dolor y la facultad de desear." (KANT, I. Crítica del Juicio (Trad. M. García Morente) Espasa-Calpe, Madrid, $1981^{2}$, Introducción, III, p. 76). A. Pintor-Ramos mantiene la idea de que el conocimiento zubiriano de la estética kantiana parece estar condicionado por el estudio que sobre ella realizó M. García Morente en su tesis doctoral La estética de Kant (1912), y que luego antepuso a su traducción de La Crítica del Juicio (1914) (cf. PINTORRamos, A., Nudos en la filosofía de Zubiri, Publicaciones Universidad Pontificia de Salamanca, 2006, p. 141, n. 30); muy bien podría ser así; pero seguramente Zubiri tenía en 1975 un conocimiento algo más profundo del pensamiento kantiano sobre este particular, pues en su biblioteca personal, además de las Werke de Kant, editadas por Bruno Cassirer (11 vols.), se encuentra la edición de la Kritik der Urteilskraft publicada por Alfred Baeumler en 1923, así como el estudio de Walter Frost Der Begriff der Urteilskraft bei Kant, que vio la luz en 1906.

$18 \mathrm{SV}, \mathrm{pp} .332-333$; los subrayados son míos.

19 Cf. ZUBIRI, X., Sobre la realidad (SR) (1966), Alianza / Fundación X. Zubiri, 2001, p. 24.

${ }^{20}$ Cf. ZUBIRI, X., Sobre la esencia (SE), Alianza / Fundación X. Zubiri, 19724, p. 452 , y Sobre el hombre (SH), Alianza / Fundación X. Zubiri, Madrid, 1998², p. 480.

${ }^{21}$ SR, p. 32. 
realidad; y ante esa realidad, que ocasiona en él una tensión o desequilibrio, no responde de manera automática, sino que se ve obligado a optar, es decir, está obligado a decidir la forma de realidad que para sí mismo desea adoptar o apropiarse 22 .

Ahora bien, ante la solicitación proveniente de la realidad y la modificación del tono vital que provoca en el ser humano, éste alcanza a sentirse de determinada manera en la realidad: "El sentimiento es [por consiguiente] un modo de estar (...) en la realidad, de sentirse en la realidad"23. Con esto cae por tierra la distinción escolástica, anteriormente mencionada, entre apetitos "inferiores" y "superiores": el hombre experimenta un único estado sentimental ante la realidad, aunque éste se module de muy diversas maneras; $y$ por eso el sentimiento se refiere en él a algo real, no a un referente imaginario, ni a un ente de razón; por eso también el animal tiene "afecciones", que suponen modificaciones de su tono vital, pero no "sentimientos", ya que su sentir se enfrenta a objetos, pero no a "realidades", es decir: le falta la aprehensión de la formalidad o el momento de la realidad. Es la realidad, en definitiva, el principio formal del tono sentimental; dicho de otra manera: el sentimiento "es el principio tónico de la realidad"; pues mientras el animal tiene simples "afecciones", el hombre tiene sentimientos afectantes 24 : "afectantes" por lo que tienen de estimulación tónica animal; "sentimientos" por la aprehensión del carácter de realidad que suponen 25 .

Todo sentimiento, según Zubiri, implica esta formalidad de realidad; todo sentimiento es "sentimiento de realidad", ya que todo sentimiento supone una tonalidad provocada por algún tipo de realidad, respecto de la cual el hombre queda "temperado"; de manera que mediante el sentimiento, el hombre queda "atemperado a la realidad", acomodándose a ella: "la esencia formal del sentimiento -nos dice- es ser atemperamiento a la realidad"26. De ahí que los sentimientos no sean algo meramente subjetivo, como suele creerse, sino que se refieren esencialmente a una realidad que, de alguna manera, nos está presente; dicho de otro modo: los sentimientos son actos del sujeto; pero no por eso son subjetivos, pues envuelven formalmente un momento de realidad, realidad que, por hallarse presente al sentimiento, es de él. Zubiri aclara que este "de" no implica

22 Cf. ZUBIRI, X., "El hombre, realidad personal", en: Escritos menores (1953-1983)

(EM), Alianza / Fundación X. Zubiri, Madrid, 2007, pp. 39-63.

23 SV, pp. 333-334.

24 Ibidem.

25 Sobre la inserción afectante y temperativa del hombre en la realidad, cf. ZUBIRI, X., Inteligencia sentiente (IS) Tecnos / Fundación X. Zubiri, Madrid, 2004, pp. 119-120.

26 SV, pp. 334-335. 
ningún tipo de conexión causal entre realidad y sentimiento, ni tampoco que los sentimientos sean fenómenos intencionales en el sentido husserliano: los sentimientos no están conectados con la realidad ni causal, ni intencionalmente, sino de una forma mucho más elemental, que Zubiri llama "genitiva" 27 , tomando este término en el sentido que adopta en las lenguas semíticas: la realidad lo es de la inteligencia que la aprehende, de la voluntad que la apetece y del sentimiento al que afecta; y en cada una de esas dimensiones, la realidad cobra un carácter diferente, carácter que pertenece a la realidad misma: "Es la realidad misma -afirma Zubiri- la que es entristeciente, la que es alegre, la que puede ser amable, antipática u odiosa"28; y nada obsta a ello que unos sientan la realidad de una manera y otros de otra; pues la realidad no tiene por qué ser la misma para todos: puede ser diferente, sin dejar de ser real.

Gracias a su enfrentamiento con la realidad, las cosas se le hacen presentes al hombre de una forma determinada; a esa manera de hacerse presentes, de "quedar" ante el hombre, la denomina Zubiri su "actualidad"; Zubiri entiende las cosas como sistemas de notas reales, pero aclara explícitamente que la actualidad no es una nota real que se añada a la cosa, sino que es una manera de presentarse la realidad misma ante el hombre, bien ante su inteligencia, bien ante su voluntad, o bien ante su sentimiento; asimismo, aclara Zubiri que "actualidad" no es lo mismo que "presencialidad": las cosas le son presentes al hombre porque "quedan" o se hacen "actuales" ante él de cierta forma. "La unidad del hacer que las cosas queden y del quedar de las cosas, es justamente lo que constituye el $d e$ "; y es esa unidad la que permite diferenciar "la nuda realidad" de la "actualidad", pues algo puede ser real sin tener que actualizarse; en cambio, para que algo sea actual es necesario que haya una realidad, es decir, ha de ser constitutivamente "actualidad 'de' una realidad"29.

De ahí que el sentimiento posea un carácter no-subjetivo: porque el carácter de actualidad, por ser de una realidad, califica a la realidad misma; ésta se actualiza de manera diferente ante el sentimiento que ante la inteligencia, o ante la voluntad: ante la inteligencia se actualiza como "verdad" [o "lo verdadero"] (verum); ante la voluntad, como "bondad" [o "lo bueno"] (bonum), y ante el sentimiento "se nos actualiza y presenta como atemperante" 30 . Así pues, si como afirma la filosofía de Zubiri, el carácter fundamental de la realidad es ser "de suyo"31, entonces este "de

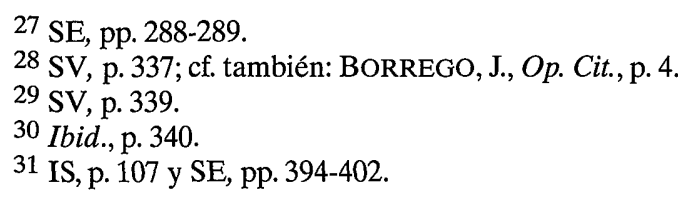


suyo" puede actualizarse de tres formas: en forma de verdad, en forma de bondad y en forma de atemperamiento frente a lo real ${ }^{32}$.

Tras este análisis, el sentimiento se nos aparece como un modo de apertura, entre otros, a la patencia de lo real, que puede manifestarse de dos maneras: como fruición o gusto, y como disgusto ${ }^{33}$, parámetros a los que pueden reducirse todos los demás sentimientos: alegría, amor, compasión, miedo, tristeza, etc.

Acabamos de decir, además, que ante el sentimiento la realidad aparece como atemperante; lo que significa que la realidad posee una cualidad intrínseca, propia: la temperie, y que es esta cualidad la que se actualiza en el sentimiento: "La realidad -afirma tajantemente Zubiri- no es pura y simplemente el área de lo verdadero y el área de lo bueno, es también el área de la temperie." Desde este punto de vista, "los sentimientos no son meramente subjetivos, [sino que] todos los sentimientos nos presentan facetas de la realidad, no solamente estados míos"34.

Como estamos viendo, Zubiri concede enorme importancia al sentir, y al "carácter 'videncial' del sentimiento" 35 , término que hay que entender en su estética en un sentido profundo y amplio, como el fruto de una articulación orgánica entre tres vocablos etimológicamente vinculados entre sí: el sentido (entendido como facultad sensible), el sentimiento (afecto) y el sentido (entendido como significado); según López Quintás, la conexión que se establece entre estas tres dimensiones del sentir es la que permite a Zubiri entender primero los sentidos "como vehículos natos de acceso a los estratos metasensoriales de la realidad", y a partir de ellos, el sentimiento como aquello que "nos abre a ámbitos de realidad" cada vez más amplios. Zubiri, afirma López Quintás, "confiere alto rango a los sentidos no por sensoriales, sino por sentimentales, es decir, por estar abiertos constitutivamente a la trascendencia de lo profundo metasensible" 36 , al senti$d o$, en su acepción más elevada, profunda y plena. Es el sentimiento, mediado por la inteligencia sentiente ${ }^{37}$, el que permite al ser humano partici-

32 Por eso sentimos que un objeto, una acción o una persona -reales o representados en una obra de arte literaria, cinematográfica, musical, pictórica, etc.- nos estremecen hasta lo más profundo, o resultan escalofriantes; o suscitan en nosotros una sensación de elevación, euforia, alegría intensa, comicidad...: el sentimiento humano se atempera a esas diferentes realidades, que lo conmueven de muy diversas maneras.

33 SV, p. 340.

34 Ibid., p. 342.

35 SH, p. 479.

36 LÓPEZ QUINTÁs, A., "Xavier Zubiri. La inteligencia sentiente y el estar en realidad", en: Filosofía española contemporánea, BAC, Madrid, 1970, p. 202.

${ }^{37}$ Cf. GUY, A., Historia de la filosofía española, Anthropos, Barcelona, 1985, p. 423. 
par en la realidad por vía de la apertura esencial; pues "sentir, en suma, no es un mero hacerse cargo intencional de ciertos datos sensibles, sino la instauración misma de un vínculo ambital de participación en la realidad"38.

En este sentido, López Quintás ha destacado el papel que juega el sentido del tacto en la estética de Zubiri: si, de acuerdo con lo expuesto en Sobre la esencia, el "de suyo", la interioridad de las cosas -entendidas como sistemas clausurados de notas, o sustantividades-, "se halla actualizada en exterioridad" 39 , entonces, a través de su superficie externa, captada hápticamente, es posible crear un "ámbito de vibración" que nos permita penetrar en su intimidad más profunda, tocar la intimidad de "su corazón": En el "campo abierto" de la sensibilidad se nos abre también la realidad por dentro, en su sentido, como sucede en el terreno de la intelección, pero en un plano afectivo, temperante, vinculado, en palabras de Quintás, a una "encrucijada viviente" de los caminos naturales que intervinculan la mente y las cosas (...), [fundando] respecto a lo real un modo singular de vecindad a nivel de hondura. Por eso en la intimidad del sentir se alía la cercanía con la reverencia, la inmediatez de la percepción y la perspectiva de la reflexión, la turgente plenitud del tacto y la estratégica distancia de la comprensión. El trato con la intimidad radical de las cosas que viene dada por sus internos principios constitutivos se traduce, así, en un modo de conocer eminente, por bipolar: la sabiduría, forma de sentir ineludiblemente vertida hacia el ser real y verdadero"40. Se está hablando aquí, como puede verse, de un saber sentimental, que tiende hacia lo profundo, como fuente de una realidad, cuya verdad no se nos da como concepto, ni como objeto de preferencia moral, sino como un "ámbito de realidad abierto por el sentir, (...) y que implica una visión en amplitud y hondura que penetra en la raíz misma de la sustantividad de las cosas reales (...), [constituyendo] el único modo fecundo de arraigo"41. Vamos a ver, a continuación, cómo esa capacidad característica del sentimiento para abrirnos a la profundidad de lo real alcanza su máxima expresión en el sentimiento estético: es en él donde se nos hace patente, a modo de estremecimiento cordial, el carácter enigmático de la realidad ${ }^{42}$, en toda su abismal grandeza.

${ }^{38}$ LÓPEZ QUINTÁs, A., "Xavier Zubiri. La inteligencia sentiente y el estar en realidad", Op. Cit., p. 203.

39 SE, p. 493.

40 LÓPEZ QUINTÁs, A., Xavier Zubiri. La inteligencia sentiente y el estar en realidad", Op. Cit., p. 204.

41 Ibid., pp. 205-206.

42 Sobre el carácter constitutivamente enigmático de lo real, cf. ZUBIRI, X., El hombre y Dios (HD), Alianza / Fundación X. Zubiri, Madrid, 20037, pp. 97-100. 


\subsection{El sentimiento estético como "dimensión" de lo real}

Como acabamos de decir, Zubiri se adentra en la estética, de la mano del sentimiento ${ }^{43}$, al que va a reivindicar para el panorama artístico contemporáneo. Ya hemos señalado que el sentimiento, en tanto que referido a la realidad, se reduce, en última instancia, a dos dimensiones fundamentales: la fruición y el disgusto; pues bien, si esto es así, el sentimiento estético se diferenciará de otros sentimientos por el goce característico que produce. En general, el sentimiento de goce se refiere a las cualidades que posee una realidad concreta; pero cuando el goce no se refiere a las cualidades que pueda tener un objeto real, sino que se refiere simplemente al hecho de que ese objeto es real, entonces el sentimiento que se suscita en nosotros es el sentimiento estético. Dicho sentimiento se basa en la fruición de algo real, simplemente porque es real; de lo que cabe concluir que "la complacencia en lo real como real es justamente (...) la esencia del sentimiento estético"44.

Esta caracterización confiere una peculiar especificidad al sentimiento estético respecto de los demás sentimientos, porque tales sentimientos se refieren a distintas formas de atemperarse a lo real, mientras el sentimiento estético se refiere intrínseca y formalmente a la simple actualidad de lo real, por lo que no se trata de "un sentimiento más entre otros, sino [que supone] una dimensión constitutiva, más o menos larvada, de todo sentimiento. (...) Todo sentimiento envuelve intrínseca y formalmente una componente estética"45.

Cabe concluir, por tanto, que el sentimiento estético no es un misterioso estado subjetivo, íntimo, sino que "es la dimensión de actualidad de lo real propia de todo sentimiento", un sentimiento de fondo, que acompaña a cualquier otro sentimiento, pero que sólo cuando se constituye en centro de reflexión aparece dotado de una dimensión especial. "Lo estético -aclara Zubiri- puede y debe ser tomado en y por sí mismo, pero sólo como dimensión. Y entonces lo estético puede convertirse incluso en objeto de una ciencia de lo estético: la Estética. Pero jamás se debería convertir una dimensión [de lo real en cuanto dado al sentimiento] en estado [sentimental subjetivo]" 46 ; no obstante, aunque el sentimiento y el goce estéticos no son subjetivos, sí lo son por lo que se refiere a la pluralidad de

\footnotetext{
${ }^{43}$ Cf. Borrego, J., Op. Cit., p. 2.

44 SV, pp. 345-346; cf. también Borrego, J. Op. Cit., p. 6.

45 SV, p. 347.

${ }^{46} \mathrm{SV}, \mathrm{pp} .347-348$.
} 
sentimientos estéticos concretos en los que se manifiestan, que pueden variar con los individuos, con las mentalidades y con las distintas épocas ${ }^{47}$.

$\mathrm{El}$ curso del razonamiento que acabamos de seguir le conduce a $\mathrm{Zu}$ biri a realizar -en contra de su propósito inicial- una breve incursión por la filosofía del arte, y a rechazar una de las tesis fundamentales de la estética hegeliana, a saber, aquella según la cual el Arte es expresión de la vida espiritual48; porque -dice- "lo esencial (...) de la obra de Arte no es ser expresión de la vida del Espíritu, sino expresión de la actualidad de la realidad en mí como realidad. (...); no es una expresión de la vida del espíri$\mathrm{tu}$, sino una expresión de la manera como en esa vida se hace actual lo real; es una expresión de lo actual de la realidad misma", tal como se ofrece al sentimiento; por eso, "el fenómeno primario en el orden del sentimiento, del sentimiento estético, es la presencia actualizada de la realidad. (...) La expresión de esta actualidad constituye precisamente el Arte"49: al igual que la actualidad primaria de la realidad ante la inteligencia como verum se estudia en la Lógica, y la actualidad primaria de la realidad ante la voluntad se expresa como bonum en la Ética, la actualidad primaria de la realidad en el sentimiento temperante del hombre adquiere el carácter de lo bello (pulchrum), objeto de estudio de la Estética, y se expresa a través del Arte. De esta manera, como afirma Javier Borrego, Zubiri busca

\section{SV, p. 350.}

48 HEGEL, G. W. F., Lecciones sobre la estética, Op. Cit., pp. 77-78: “(...) Debido a la ocupación con lo verdadero en cuanto objeto absoluto de la consciencia, el arte también pertenece a la esfera absoluta del espíritu y por ello se halla, según su contenido, en uno y el mismo terreno que la religión, en el sentido más específico de la palabra, y que la filosofía. (...) Desde esta igualdad de contenido, los tres reinos del espíritu absoluto sólo se diferencian por las formas en que lleva a la consciencia su objeto, lo absoluto.

Las diferencias entre estas formas residen en el concepto del espíritu mismo. El espíritu en cuanto espíritu verdadero es en y para sí, y, por ello, no una esencia abstractamente más allá de la objetualidad, sino, dentro de ésta, el recuerdo del espíritu finito de la esencia de todas las cosas: lo finito que se capta en su esencialidad y, por tanto, ello mismo esencial y absoluto. Ahora bien, la primera forma de esta aprehensión es un saber inmediato y, precisamente por eso, sensible, un saber con la forma y la figura de lo sensible y objetivo mismo, en que lo absoluto accede a la intuición y el sentimiento. La segunda forma es la consciencia representativa [religión], la tercera, finalmente, el libre pensar del espíritu absoluto [filosofía].

Ahora bien, la forma de la intuición sensible [del espíritu] pertenece al arte, de modo que el arte es lo que presenta la verdad en modo de configuración sensible para la consciencia, y ciertamente de una configuración sensible que en esta apariencia suya misma tiene un sentido y un significado superiores, más profundos, sin no obstante, querer hacer aprensible a través del medio sensible el concepto como tal en su universalidad; pues precisamente la unidad de éste con la apariencia individual es la esencia de lo bello y de su producción por el arte."

49 SV, p. 351. 
"el origen del arte a través de la forma en la que la realidad se nos presenta, es decir, a través de la forma en la que nos afecta la realidad estéticamente" 50 . El Arte es "una expresión de cómo la vida se hace actual en lo real; (...) una expresión de lo actual de la realidad misma" 51 ; es, parafraseando a Heidegger, la puesta en obra de la realidad en cuanto realidad. $\mathrm{El}$ arte es capaz de crear ámbitos que, aprehendidos en instantes de especial intensidad, nos abren "una puerta hacia realidades ambitales que introducen al ser humano en espacios fruitivos extremos (...), espacios que indican realidades que, al ser mayores, producen mayor éxtasis estético." Las grandes obras de arte sólo se diferencian de las meramente talentosas porque su potencial para hacernos penetrar en ámbitos enormes de realidad, y su capacidad de encumbrar al hombre hasta hacerle "conocer la inmensidad" 52 , es mucho más elevado.

\section{El problema de lo bello (el pulchrum)}

\subsection{Determinación del pulchrum}

Un fragmento del emotivo "Recuerdo" que Zubiri dedicó en 1976 a su amigo el poeta Luis Felipe Vivanco puede servirnos muy bien para resumir su teoría recién expuesta, en la que se conectan sensibilidad, realidad, belleza (pulchrum) y arte (representado en el texto por la poesía):

“(...) las formas de realidad no simplemente son verdaderas, es decir, no son simplemente lo que son efectivamente en sí mismas -es la verdad 'real' de todas las cosas-. Tampoco consiste simplemente en que las cosas, además de verdaderas, sean más o menos 'convenientes' para decisiones voluntarias y para resolver los problemas de las situaciones que el hombre se encuentra en su vida. Es que la realidad tiene además un carácter que yo he llamado alguna vez 'atemperante'. Consiste en ser aquello a lo que el hombre se atempera en realidad. $Y$ los modos de atemperarse a la realidad es justamente lo que llamamos sentimientos (...) [o] sensibilidad. Poco importa para el caso. Con uno u otro vocablo, lo que se quiere designar es que la realidad no es sim-

50 Borrego, J., Op. Cit., p. 1.

51 Ibid., p. 6.

52 Ibid., p. 11; así Borrego; sin embargo, por mi parte creo que sería más adecuado decir que el gran arte nos permite sentir la inmensidad, pues toda la argumentación zubiriana sobre la estética, al resultar inseparable de su noción de inteligencia sentiente, acentúa en este terreno el papel del sentimiento, frente al cual pasa a un segundo (aunque desde luego imprescindible) plano la intelección. 
plemente algo verdadero y algo bueno, sino que es también algo a lo que el hombre se atempera y lo siente atemperándose a ello. Es lo que de una manera radical debe llamarse el $\chi \alpha \lambda o ́ v$, la belleza. La realidad no es sólo verdadera y buena, es también pulcra. Y cuando esta realidad y este modo de sentir las cosas, de sentirse atemperado en ellas, se hace y se expresa en palabras, entonces me imagino que es cuando puede nacer la poesía" 53 .

Desde esta concepción, Zubiri glosa la concepción kantiana de lo bello, basada en el desinterés ${ }^{54}$ : ciertamente la contemplación estética tiene un carácter desinteresado, pero ese carácter no es negativo, sino positivo, pues hace referencia al carácter de las cosas como realidad, independientemente de sus caracteres talitativos, que las constituyen de tal o cual manera.

Ante el sentimiento, la realidad se abre bajo el carácter de "pulchrum", es decir, en su dimensión de "belleza":

"La verdad, la belleza y el bien son en este sentido los tres modos intrínsecos como la realidad efectivamente está actualizada en el hombre. Ante el hombre no está actualizada solamente como inteligencia y después, como un apéndice, con el sentimiento y la voluntad, no. La realidad está actualizada según tres modos que son formalmente distintos entre sí, por muy conexos que se hallen (...). Esos tres momentos del pulchrum, del verum y del bonum son algo que pertenece congéneremente a la realidad, a ella en sí misma, en tanto que es actual en la inteligencia, en la voluntad y en el sentimiento del hombre"55.

Esto significa que las cosas "son bellas en sí mismas", y que dicha belleza consiste única y exclusivamente en una peculiar actualización de las cosas ante el sentimiento, en tanto que reales; la belleza no es, pues, una cualidad que se añada a las cosas extrínsecamente, sino que es un modo en que la realidad se hace presente ante el sentimiento del hombre; la belleza, por otra parte, tampoco se identifica con un determinado "valor", como creían Scheler, N. Hartmann, y probablemente Ortega ${ }^{56}$, sino que se

53 EM, pp. 271-272.

54 Kant, en la Crítica del Juicio, KU, I, 1, 1, § 2, afirma que "la satisfacción que determina el juicio de gusto es totalmente desinteresada" (Das Wohlgefallen, welches das Geschmacksurtheil bestimmt, ist ohne alles Interesse) (KANT, I., Crítica del Juicio, Op. Cit., I, 1, $1, \S 2$, p. 102).

55 SV, p. 356.

56 Zubiri rechaza explícitamente que la belleza sea un valor en SV, p. 357; se opone así a la tesis axiológica compartida por muchos estetas del siglo $\mathrm{XX}$, vinculados de un modo 
reduce a una manera de actualizarse las cosas: si no hubiese seres humanos, las cosas no perderían esa cualidad; pero tampoco la adquieren merced a la existencia de los hombres; lo que pierden o adquieren, en función de la existencia del ser humano, es la actualidad de esa propiedad, que les pertenece a las cosas por sí mismas ${ }^{57}$.

\subsection{Los tres estratos de la belleza}

Establecido que la belleza pertenece a las cosas mismas, Zubiri profundiza en su análisis de dicha propiedad, encontrando que en la belleza pueden descubrirse tres estratos diferentes 58 :

$\left.1^{\circ}\right)$ Un primer estrato, por el que consideramos las cosas como término de la fruición estética en su realidad, y en el que surge inmediatamente la dualidad entre cosas bellas y feas, siendo "bellos" aquellos objetos que están bien hechos, es decir, que poseen perfección, y "feos" aquellos otros que no lo están, es decir, que adolecen de imperfección. En este primer estrato (que podríamos ejemplificar con el Doríforo, una talla románica de la Virgen o una Madonna de Rafael), "bello" o "hermoso" equivale a "perfecto", mientras "feo" equivale a "deforme"59. Corresponde este nivel, en el orden del sentimiento, al que representa en el orden de la intelección -expuesto en la trilogía sobre la inteligencia (1980-1983)- la aprehensión de lo que algo es "en realidad" por la razón 60 ; ésta forja, es decir, inventa, crea libremente los sistemas de referencia o cánones que determinan a lo largo de la historia qué se considera "bello" o "feo" / "perfecto" o "imperfecto" dentro de lo real, marcando así los diversos estilos

u otro a la fenomenología, como Nicolai Hartmann (cf. Ästhetik, Walter de Gruyter, Berlin, 1953, pp. 322-362 [Trad. Cast. de E. Cecilia Frost: Estética, UNAM, México, 1977, pp. $377-$ 424]), Dietrich von Hildebrand (Cf. HILDEBRAND, D. von, Gesammelte Werke, Band V: Äs thetik, 1. Teil, Habbel / Kohlhammer, Stuttgart, 1977, Kap. 1-2), o el propio José Ortega y Gasset en su conocido ensayo de 1923 Introducción a una estimativa. ¿Qué son los valores? (Encuentro, Madrid, 2004).

$57 \mathrm{SV}$, p. 358.

58 La fundamentación del objeto estético a través de la teoría de los estratos tiene sus antecedentes en Nicolai Hartmann (Ästhetik, Op. Cit., pp. 74 y ss. [Estética, Op. Cit., pp. 90 y ss.]) y Roman Ingarden (cf. INGARDEN, R. "Concreción y reconstrucción", en: WARNING, R. (Ed.), Estética de la recepción, Visor, Madrid, 1989, pp. 35 y ss.) No parece que Zubiri haya manejado la Ästhetik de Hartmann, aunque sí leyó sin duda Das Problem des Geistigen Seins, puesto que en su Biblioteca existe un ejemplar de esta obra, fechado en 1933; en ella Hartmann ofrece un anticipo de la doctrina de los estratos que desarrollaría luego más minuciosamente en su principal obra estética, publicada póstumamente.

59 Ibid., p. 359.

60 IS, p. 317. 
artísticos: clásico, románico, gótico, renacentista, barroco, romántico, etc. Dichos sistemas de referencia establecen el repertorio de posibilidades de apreciación estética y de creatividad que existen dentro de una determinada época histórica. Éstos determinan qué idea de belleza es apreciada por el hombre clásico, medieval, renacentista, barroco, romántico, etc., y, en general, qué considera "perfecto" o "imperfecto" la mentalidad (o forma mentis) correspondiente a un período histórico específico. A juicio de Zubiri, es exclusivamente en este estrato donde hay que localizar la tan traída y llevada relatividad de lo bello, porque tanto el canon de "lo clásico", como qué cosas se consideran hermosas o feas, perfectas o imperfectas, es algo que va cambiando a lo largo de las épocas históricas, y que incluso varía dependiendo de cada individuo; Zubiri señala, asimismo, que tales cambios dependen sobre todo de que el sistema de referencia, o estilo vigente, agote o no sus posibilidades de creatividad, azuzando así a la razón sentiente para que explore otras posibilidades de creación, mediante un cambio de dirección en la sensibilidad estética.

$2^{\circ}$ ) En el segundo estrato, lo que complace son las cosas precisamente por ser reales. En este estrato también es posible alcanzar el goce estético de las cosas feas, porque ellas también forman parte de la realidad. Mientras, consideradas desde el estrato anterior, las cosas feas no pueden ser disfrutadas, consideradas desde este segundo estrato, la realidad puede gozarse estéticamente, a pesar de su posible fealdad. En este estrato (que podríamos visualizar con los objetos reales que quizás sirvieron de base para crear las obras anteriormente mencionadas: por ejemplo, un atleta griego, o una campesina italiana, con las imperfecciones que como seres reales esas personas pudieron tener) todas las cosas son, en cierto sentido, bellas. Correspondería, en el orden del sentimiento, a lo que significa en el ámbito de la intelección la aprehensión de cualquier cosa real dentro del campo de realidad del que forma parte, esto es, en su relación de respectividad con las demás cosas reales que la rodean; aquí se selecciona, por tanto, un sector o campo de lo real, enfocado desde cierto punto de vista, el cual viene siempre determinado por el estrato anterior, es decir, por el sistema de referencia adoptado en un determinado momento histórico, que actúa como "estilo dominante". Este nivel coincide, en el plano del sentimiento, con la aprehensión de "lo que algo es en la realidad", propia del logos sentiente ${ }^{61}$; sobre él se alza, después, la re-

61 Sería un mérito del arte contemporáneo -como el realizado por A. Tàpies-el haber profundizado en este estrato de la fruición estética, ya que se centra en las cualidades pura- 
presentación de la realidad que nos ofrece el arte de cada época (estrato $\left.1^{\circ}\right)$.

$3^{\circ}$ ) Queda un último estrato, en el que las cosas se disfrutan simplemente en cuanto realidad, es decir, en su momento inespecífico de realidad, cualquiera que ésta sea; se trata del sentimiento estético general, en tanto que recae sobre el ámbito mismo de realidad en cuanto tal; aquí nos enfrentamos a lo real como kalón, como pulchrum, dado a la simple impresión de belleza (como, por ejemplo, la que experimenta un artista ante la naturaleza, un bodegón, o el cuerpo humano que luego va a trasladar a su cuadro). Este tercer estrato de lo bello no está separado de los anteriores -al contrario de lo que pensaba Platón, quien hablaba de "lo bello en sí" como entidad apartada del mundo real, perteneciente al mundo de las Ideas-; sino que, según Zubiri, el pulchrum "se encuentra en las cosas bellas, y fuera de ellas no tiene realidad ninguna"; pero, a su vez, no se identifica con tales cosas, sino que remite, en cada cosa bella, a todas las demás cosas bellas. Por consiguiente, el pulchrum tiene una dimensión de trascendencia, aunque no se sitúa por encima de las cosas reales, en una suerte de Kosmos noetós platónico, sino que reside "en las cosas bellas, reales y concretas" 62 . Siguiendo la relación anteriormente pergeñada con los niveles de la inteligencia sentiente en su actividad cognoscitiva, podría decirse que este estrato corresponde en el orden del sentimiento a lo que es la intelección de la realidad propia de la aprehensión primordial, es decir, aquella aprehensión que capta lo real "en y por si mismo"63; y, como sucedía en el caso anterior, también se encuentra históricamente condicionado por el sistema de referencia (estilo o canon de belleza-fealdad / perfección-imperfección) establecido por la razón sentiente en un determinado momento de la historia. Es, sencillamente, la aprehensión estética inmediata de la realidad, o "sensación estética de fondo" -por llamarla de algún modo-, propia de cada momento histórico, sobre la cual se seleccionan determinados campos estéticos de la realidad (estrato $2^{\circ}$ ), que sirven para construir luego el mundo del arte (estrato $1^{\circ}$ ).

mente matéricas de los objetos y en su simple carácter de realidad, con independencia de que a tales objetos puedan aplicárseles los calificativos de "bellos" o "feos": cf. BORREGO, J., Op. Cit., p. 7.

62 SV, pp. 367-368.

63 IS, p. 192. 


\subsection{Copertenencia y limitación del pulchrum}

La principal conclusión que cabe extraer de lo dicho hasta el momento es que el pulchrum se caracteriza, en primer lugar, por su copertenencia, es decir, por el hecho de que todas las cosas son, bien bellas, bien feas, debido a la limitación intrínseca que afecta a toda la realidad 64 . "Precisamente porque todas las realidades son limitadas, tienen la doble posibilidad de ser bellas o de ser feas", dice Zubiri; y es justo dicha limitación lo que hace posible que exista dentro de la realidad lo feo. Con todo, $\mathrm{Zu}$ biri considera que el aspecto positivo y el negativo de la belleza, aunque se copertenecen, no equivalen, sino que en la realidad predomina (tiene más peso) siempre el aspecto positivo, bello, sobre el negativo y feo65.

\subsection{Unidad de los tres estratos, apertura y expresividad de la belleza}

¿Existe algún tipo de conexión o de unidad entre los tres estratos recién mencionados? Zubiri afirma taxativamente que dicha unidad existe, pero no puede ser la unidad de "la belleza" en el sentido platónico del término; es decir, no ha de pensarse que el primer estrato (las cosas por ser reales) y el segundo (las cosas hermosas y feas) son sólo una proyección del tercero (la realidad como pulchrum), pues esto implicaría sustantivar la belleza, hipostasiarla, como si se tratase de una "cosa bella" superior. También rechaza Zubiri la idea de la unidad de contracción, característica de la teoría del ser de la Escolástica, según la cual el pulchrum "se contrae" en las cosas bellas, pues Zubiri considera que, aunque la contracción es, quizá, un rasgo aplicable al concepto abstracto de belleza, no lo es en modo alguno a las cosas bellas consideradas en sí mismas. Una última posibilidad, representada por San Agustín o Heidegger, propone considerar la unidad de los tres estratos como unidad de manifestación (de manera que cada estrato manifestaría los anteriores); pero Zubiri también rechaza esta alternativa -no queda muy claro por qué-, y mantiene que la unidad de los tres estratos se da como actualización.

64 Sobre la limitación de lo real, cf. SE, p. 463: “(...) la limitación pertenece intrínsecamente al 'de suyo' mismo. Lo real es 'de suyo', pero es 'de suyo' limitado como realidad; lo real es 'realmente limitado"'.

$65 \mathrm{SV}$, p. 369. 
Actualización que supone, a su vez, una expansión, por la que cada estrato se funda en el anterior; dicho de otro modo: lo que llamamos estratos no son sino distintos aspectos de la realidad en su actualización; "no es lo mismo -indica nuestro autor-actualizar una cosa por las buenas cualidades que tiene, que por ser real, y que por ser un momento del ámbito de realidad"66; al ser el pulchrum, la belleza, algo abierto, esa apertura implica que cada estrato actualiza y conserva, expresándolo, el estrato inmediatamente anterior: "Las cosas bellas son expresión del pulchrum, como las cosas hermosas y las cosas feas son expresión positiva o negativa de lo que es la belleza"67. La unidad última y radical de la realidad, en cuanto pulchrum, se da como actualidad expresiva, como expresión, ante el sentimiento temperante. Todo arte es, por tanto, expresivo, más allá de las corrientes artistas que específicamente puedan autodenominarse "expresionistas".

\subsection{Fundamento material de la belleza}

La pregunta que inevitablemente se plantea a continuación es: ¿sobre qué se apoyan estos tres estratos, expresivamente ligados entre sí? En la filosofía de Zubiri, la forma primaria en que se actualiza la realidad ante el sentimiento es pura y simplemente la materia, no entendida como estructura material del objeto (por ejemplo, su estructura atómica), sino en su función más inmediata, "somática", por la que una realidad cualquiera (por ejemplo, la de un hombre) se nos presenta actualmente. Ahora bien, la forma de presentarse somáticamente la materia es, ante todo, como expresión (por ejemplo, la fisonomía de este o de aquel hombre concreto); y dicha expresión requiere siempre lo que Zubiri llama "espaciosidad", es decir un ámbito de posible actualización referencial del conjunto de las cosas materiales, en su respectividad mutua ${ }^{68}$.

Considerando la actualidad de la materia como el fundamento imprescindible de cualquier otra actualidad, parece evidente que la actualización de todos los estratos que integran lo estético implica, en última instancia, como condición de posibilidad, su fundamentación en la materia,

$66 \mathrm{SV}$, p. 372.

67 SV, p. 373.

68 Sobre la materia como principio de actualidad, como "materia somática", que envuelve la "presencialidad física" de un objeto, suponiendo la "espaciosidad" del mismo, cf. ZuBIRI, X., Espacio. Tiempo. Materia (ETM), Alianza / Fundación X. Zubiri, Madrid, 20012, pp. 108 y ss., pp. $150-157$ y $360-374$. 
algo que se pone de manifiesto también, con rotunda claridad, en las obras de arte ${ }^{69}$ :

\begin{abstract}
“(...) todos los estratos de lo estético están fundados en la materia. (...) Y no me refiero con esto únicamente a la belleza natural sino también a la belleza de las obras artísticas; todas, incluso las literarias. Ninguna obra de arte consiste pura y simplemente en lo que el artista ha imaginado y forjado en su cabeza o sentido en su alma. Todo ello hay que expresarlo de alguna manera: sólo entonces tenemos una obra de arte. Y esto se extiende también al caso de la literatura: en ella la materia es principio de actualidad significativa. (...) De ahí la enorme importancia que tienen los materiales en la obra de arte. Su función no es sólo contribuir a ella por su mejor o peor calidad, para producir mejores combinaciones de colores o de sonidos, o de formas arquitectónicas o esculturales, sino que su función formalmente esencial es la manera de dar actualidad, mejor o peor, de un modo concreto a aquello que el artista entiende por realidad bella. La función de los materiales en la obra de arte es la de ser actualidad de lo bello"70.
\end{abstract}

\title{
5.6. El pulchrum como carácter trascendental de la realidad
}

En la filosofía escolástica se llamaba "trascendentales" a los caracteres compartidos por todas las cosas por el simple hecho de ser, a los "modos comunes del ente", o "atributos de la realidad comunes a todos los entes": estas propiedades serían trascendentales porque "trascienden todo ser de un modo determinado". Un trascendental no sería, por tanto, una realidad, sino un modo de ser compartido por cualquier realidad ${ }^{71}$. La doctrina de los trascendentales más conocida es la de Santo Tomás, quien en De veritate, I, 1 indica que lo que el intelecto aprehende, ante todo, es el ente como ente, el ente en general, común a todos los entes, en suma, el concepto del ente; de él cabe expresar alguna de sus propiedades, como cuando se dice que es una cosa (res), que es uno (unum), o que es distin-

69 Zubiri señala que la esencia del arte es precisamente "la expresión de esta actualidad [de la materia]" SV, p. 391.

${ }^{70}$ Ibid., pp. 376-377. Zubiri se refiere, evidentemente, a lo que se denomina en arte la "expresividad de los materiales." Dicha expresividad significaría la aplicación al ámbito del arte del "materismo" zubiriano, es decir, la idea de que la principal característica de la materia es su universalidad: toda realidad mundana está esencialmente fundada en la actualidad de la materia (aunque esto no significa en absoluto que lo real posea una índole exclusivamente material): Cf. ETM, p. 413.

71 Cf. FerRater MorA, J., Diccionario de filosofia, 4, Alianza, Madrid, $1986^{5}$, p. 3314. 
to de cualquier otro ente, en cuyo caso todo ente es algo (aliquid); puede también expresarse la relación que media entre el ente y el intelecto, en cuyo caso todo ente es conforme con el pensamiento o verdadero (verum); o considerar la relación del ente con la voluntad, por la cual todo ente puede ser apetecible y, por consiguiente, bueno (bonum). "Con ello tenemos la celebre lista de los 'trascendentales': ens, (...) res, unum, aliquid, verum, bonum"72.

También se afirmaba en esta doctrina escolástica que tres de los trascendentales son convertibles ("unum, verum et bonum convertuntur"); "lo bello (pulchrum), en cambio, no se incluía entre los trascendentales, y por lo general se le reducía a lo bueno.

Por otra parte, la doctrina escolástica de los trascendentales difería de la específicamente tomista en algunos aspectos importantes; así, Suárez, en las Disputaciones Metafísicas, los denominaba "pasiones del ente" (passiones entis) 73 , distinguiendo sólo tres trascendentales: "unidad, verdad y bondad (tres tantum esse proprias passiones entis, scilicet, unum, verum et bonum)"74.

Como estamos viendo, en la filosofía de corte aristotélico-tomista, el ser mismo sería el primer y más importante carácter trascendental; pero justamente esto es lo que cambia en el realismo radical de Zubiri. Para el filósofo donostiarra, lo trascendental es lo real, la realidad misma, mientras que el ser representa algo ulterior, "la mera actualidad de lo real en el mundo"75. Partiendo de esta base, Zubiri reinterpreta los trascendentales, no como notas reales de las cosas, sino como modos de actualización de las mismas, que se encuentran por encima de cualquier talidad. Y, si el pulchrum es un carácter propio de lo real y dado al sentimiento, como hemos venido afirmando, parece evidente que también deberá ser, en algún sentido, trascendental.

También hemos visto que los trascendentales: verdad, bondad, ser..., tal como los describía la escolástica, eran convertibles, por ser aspectos del ser mismo; aplicando esta propiedad al pulchrum como carácter de la realidad, cabe preguntar si resultan convertibles entre sí la realidad y el pulchrum. La respuesta de Zubiri es que todo pulchrum es real, pero no todo lo real es bello, sino que también puede ser feo; ahora bien, como -según la copertenencia anteriormente descrita- toda realidad, por su limitación,

72 Ibid., pp. 3314-3315.

73 Ibid., pp. 3315-3316.

74 SUÁREZ, F., Disputaciones Metafísicas, I (Disp. I-VI), Gredos, Madrid, 1960, Disputación III, Sección II, 3, p. 465.

75 IS, p. 156. 
tiene que ser forzosamente bella o fea, el carácter del pulchrum, resulta convertible con la realidad, aunque como "transcendental disyunto"76 (es decir, bajo el binomio bello-feo). Con esta afirmación, Zubiri completa su "metafísica de la trascendentalidad intramundana"77, en la que Dios, en principio, no necesita aparecer en modo alguno.

\subsection{Dios y el pulchrum como carácter trascendental de la realidad}

El pensamiento de Zubiri es un pensamiento teologal, en el sentido de que en dicho pensamiento el problema de Dios (entendido este concepto en un sentido general, no exclusivamente cristiano ${ }^{78}$ ) juega un papel decisivo; la cuestión ahora es: ¿cómo conectar el concepto de Dios con la noción de belleza, tal como la ha venido desarrollando Zubiri?

Como es bien sabido, a Dios se accede, según Zubiri, a través de la vía de la religación, que apunta al fundamento absoluto de la realidad 79 ; ahora bien, si Dios constituye el fundamento de la realidad, entonces los caracteres trascendentales de ésta tendrán también su raíz última en Dios; y así lo reconocía a su manera la filosofía escolástica tradicional, cuando consideraba que la verdad y el bien como trascendentales tienen su raíz misma en el acto creador de un Dios inteligente y dotado de voluntad. Sin embargo, dicha filosofía mantenía que Dios no tiene sentimientos, por lo que el carácter del pulchrum -que, como hemos visto, está vinculado al sentimiento- carecería de fundamento divino; Zubiri, en cambio, piensa que esta argumentación es errónea, porque a su entender Dios, además de inteligencia y voluntad, también tiene sentimientos (no afectos); y al igual que ha creado las cosas en función de su Intelecto y de su Volición, también las ha creado en razón del sentimiento de complacencia que experimenta por la existencia real de tales $\cos ^{80}$.

$\mathrm{Al}$ poseer la realidad un carácter finito, limitado, sus caracteres trascendentales se dan forzosamente de manera disyunta; por eso, aun siendo creada por Dios, la realidad tiene la posibilidad de ser "verdadera" o

76 SV, pp. 380-381.

77 Ibid., p. 384.

78 Sobre este punto puede consultarse el interesante artículo de A. Torres Queiruga "Revelación y religiones en Zubiri" (cf. GRACIA, D. (Ed.), Desde Zubiri, Ed. Comares, Granada, 2004, pp. 193-231).

${ }^{79}$ Sobre la vía de la religación para llegar a Dios, cf. HD, pp. 127-133 y 151-152.

${ }^{80}$ Para Zubiri "el acto creador no solamente es inteligente y volente, sino que es además complaciente." (SV, p. 389) 
"falsa", "bondadosa" o "malvada", "bella" o "fea", y su capacidad de abrirse a esta doble posibilidad, fruto de su intrínseca limitación, no puede anularla ni siquiera la omnipotencia divina. Zubiri habla aquí de cierta "permisividad" por parte de Dios: Dios permite -en el ámbito de la estructura metafísica misma de lo real- la existencia de cosas falsas, malas o feas, en tanto que toda realidad creada por él es necesariamente limitada, siendo Él mismo, por consiguiente, el principio de esas limitaciones: es una "desgracia", confiesa Zubiri, pero a la realidad creada le es inherente una dualidad de dimensiones. Bien entendido que, aunque Dios permite la existencia de estas limitaciones, siempre otorga primacía al aspecto positivo, es decir, a "lo verdadero, lo bueno y lo pulcro sobre lo falso, lo malo y lo feo"81.

\subsection{Relación entre el pulchrum y el resto de los trascendentales}

Los trascendentales mencionados tienen una unidad intrínseca, por la que los tres caracteres de la realidad: verdad (verum), bondad (bonum) y belleza (pulchrum), se "recubren", como dice Zubiri; y se recubren porque son caracteres de una realidad cuya característica fundamental es la respectividad ${ }^{82}$, propiedad por la cual cada cosa real está constitutivamente vertida hacia las demás realidades, constituyendo lo que denominamos "mundo"; según esto, la verdad es la respectividad de lo real a la inteligencia, el bien la respectividad de lo real a la voluntad, y la belleza la respectividad de lo real al sentimiento; se trata de tres "dimensiones trascendentales del mundo", es decir, tres formas de actualizarse lo real en cuanto que mundanal; por eso se copertenecen, aunque siempre, como hemos venido diciendo, de forma disyunta y limitada 83 .

Los trascendentales forman, en conclusión, un sistema, no cerrado, sino abierto y dinámico: pues ni la verdad, ni la bondad, ni la belleza están dadas de una vez por todas, sino que corresponden a la actualización de una realidad que, en cuanto tal, "está abierta dinámicamente"; forman,

81 Ibid., p. 391; a mi entender, estas ideas se encuentran muy influidas por el intenso estudio del zurvanismo realizado por Zubiri, quien, fuertemente interesado por esta antigua religión persa, llegó a traducir varios textos del Avesta; en relación con este punto, puede leerse la entrada titulada "Zurvanismo", redactada por Zubiri para la Gran Enciclopedia del Mundo, Bilbao, Durvan, 1964, vol. 19, cols. 485-486.

82 Sobre la respectividad de lo real, cf. SE, pp. 181, 274, 287-290 y EM, pp. 173-215.

83 Ibid., pp. 387-388. 
por tanto, un sistema trascendental constitutivamente abierto ${ }^{84}$, en el que la belleza, al igual que los restantes predicados de lo real, es susceptible de modulaciones siempre nuevas e imprevisibles: no cabía esperar otra cosa de una realidad que Zubiri, de acuerdo en este punto con Bergson ${ }^{85}$, concibe como constitutivamente estética, es decir, como inagotablemente creadora.

MANuel PÉRez CoRnejo Dr. en Filosofía y Licenciado en Historia del Arte

84 Ibid., p. 389.

85 Este aspecto dinámico y creador, estético, de la realidad, lo recoge Zubiri, sin duda, de la filosofía bergsoniana, que nuestro filósofo conocía de primera mano -como lo demuestra el penetrante análisis que dedica al pensador francés en su IV Lección de Filosofía (ZUBIRI, X., Cinco lecciones de filosofía, Sociedad de Estudios y Publicaciones, Madrid, 1963, pp. 163-211). Zubiri resalta en especial el carácter creador de la evolución, tal como la concibe Bergson: la realidad en evolución es "'creadora' de algo nuevo, imprevisible por no hallarse contenido en la fase anterior" de su desarrollo; de manera que "la evolución [de la totalidad de lo real] es innovación (...) es crear, es inventar" (pp. 207-208); análogamente, para Zubiri, la realidad no es algo estático, inerte, sino que su estructura profunda es intrínsecamente "dinámica"; por eso está en condiciones de "dar de sî" producciones nuevas, más perfectas y bellas, tanto en el ámbito natural como en el espiritual, representando la creatividad artística, dentro de esa productividad generalizada, una de las máximas cotas alcanzadas por el dinamismo creador que caracteriza lo real por entero (cf. Estructura dinámica de la realidad, Alianza / Fundación Xavier Zubiri, Madrid, 1989). 